\title{
Prevalence of Human Papillomavirus Types in Women with Pre-neoplastic and Neoplastic Cervical Lesions in the Federal District of Brazil
}

\author{
Geni NL Camara, Daniela M Cerqueira*, Ana PG Oliveira*, Evandro O Silva**, \\ Luciano GS Carvalho***, Cláudia RF Martins*/+
}

Faculdade de Ciências da Saúde *Instituto de Biologia, Universidade de Brasília, ICC Sul, 70919-900 Brasília, DF, Brasil
**Hospital Regional da Ceilândia, Ceilândia, DF, Brasil ***Hospital de Base do Distrito Federal, Brasília, DF, Brasil

As a contribution to the public health authorities in planning prophylactic and therapeutic vaccine strategies, we describe the prevalence of human papillomavirus (HPV) types in women presenting abnormal cytological results in Pap smear screening tests in the Federal District, Central Brazil. We studied 129 cervical scraping samples from women whose cytological tests showed either pre-neoplastic or neoplastic lesions. Amplification of HPV DNA was performed by polymerase chain reaction using consensus primers MY09 and MY11 followed by identification of isolates by restriction fragment length polymorphism. We detected HPV DNA in $62 \%$ of the samples, including HPV-16 in 43.8\%, HPV-58 in 12.5\%, HPV-31 in 10\%, HPV-53 in 6.3\%, each of HPV-18 and HPV-33 in $3.8 \%$ of the isolates. Other types (HPV-35, -52, -66, -CP8304, -6, -11, and-CP8061) were less frequent $(=$ or $<2.5 \%$ each). The prevalence of HPV-58 was relatively higher in this population than in data in South America, but similar to results obtained in other studies in Latin America, Europe, and Eastern Asia. Case-control studies need to be carried out to establish the association between the prevalence of HPV types - specially the less frequent high-risk types - and cervical cancer.

Key words: human papillomavirus (HPV) - genotypes - prevalence - HPV-58 - cervical lesion - Brazil

In contrast to what is observed in developed countries, cervical cancer mortality in Brazil is still high. Studies on historical series show that this rate has not changed since 1985. The frequency of deaths and expected new cases for 2002 were 4005 and 17,600, respectively, which corresponds to mortality and incidence rates of 4.49/ 100,000 women and 19.82/100,000 women, respectively (Brasil 2002).

The chronic infection by certain types of human papillomavirus (HPV) is definitely related to the incidence of cervical cancer (Lorincz et al. 1992, IARC 1995) and the HPVs $-16,-18,-31,-33,-35,-45,-51,-52$, and -58 can now be considered as cervical carcinogenic agents (Muñoz 2000). Squamous carcinomas and adenocarcinomas are the most frequent cervical neoplasias, and may develop from intraepithelial lesions, easily detected in preventive cytological exams (Sherman et al. 1994).

The classification of HPVs in types is based on the analysis of the nucleotide sequence of the L1 gene (LANL 1997). From more than one hundred HPVs already identified, over 40 mucosotrophic types were isolated from anogenital, orogenital or ororespiratory mucosal lesions (Bernard et al. 1994, zur Hausen \& Villiers 1994, LANL

Financial support: Fundação de Apoio à Pesquisa do Distrito Federal and Fundação de Empreendimentos Científicos e Tecnológicos

${ }^{+}$Corresponding author. Fax: +55-61-272.1793.

E-mail: cmartins@unb.br

Received 19 March 2003

Accepted 10 September 2003
1997). The mucosotrophic HPVs are classified in low and high risk-types according to the possibility of developing malignant lesions (Mansur 2001).

The large number of HPV sequences lead to the generation of a phylogenetic tree of the papillomavirus family, based on the L1 consensus primer region. This tree includes the five papillomaviruses supergroups (AE). Mucosal or genital HPVs are included in supergroup A. Other supergroups comprise HPVs that infect human skin (B) or other vertebrates (C, D, E, S) (LANL 1997).

According to studies carried out in various countries by the International Association for Research in Cancer (IARC), the most prevalent reported high-risk HPV types, which infect the uterine cervix, are: HPV-16 (53\%), HPV18 (15\%), HPV-45 (9\%), HPV-31 (6\%), and HPV-33 (3\%) (Muñoz 2000). Lower prevalence of other phylogenetically related types is also found (Meyer et al. 1998).

Reports on the prevalence of genotypes indicate that HPV-16 is the most prevalent (Bosch et al. 1995, Muñoz 2000). Nevertheless, the frequency of other high-risk types may vary according to geographic, demographic and clinical-pathological factors (Lai et al. 1999, Hwang 1999, Lo et al. 2001) and may also be influenced by the methods used for detection (Qu et al. 1997, Meyer et al. 1998).

Phases I and II human vaccine trials against HPV are underway or at the planning stage. One difficulty in developing a vaccine is determining which types of HPV to include (Hagensee 1999), since geographical variations in the prevalence of high-risk types are observed (Giuliano et al. 2001). The aim of our study is to describe the prevalence of the different HPV types in women with preneoplastic and neoplastic lesions of the cervix, in the Federal District, Central Brazil. These data may assist the 
public health authorities in planning prophylactic and therapeutic strategies to prevent cervical cancer.

\section{MATERIALS AND METHODS}

Population - From October 1998 to August 2001, 159 outpatients were recruited from gynecology clinics in three public hospitals in the Federal District. The criterion for selection was a cytological report within the current year of cervical intraepithelial neoplasia (CIN 1, CIN 2 or CIN 3 ), squamous cell carcinoma (SCC), adenocarcinoma (ADENO), atypical squamous or glandular cells of undetermined significance (ASCUS or AGCUS) and cytological alterations suggesting HPV infection (HPV). Patients who were referred for cervical biopsies or topical therapy, after the cytological reports, were not included in our study.

All subjects were informed about the methodology and objectives of the research and signed a consent form. The physicians also registered social, demographical, epidemiological, clinical, and laboratorial data on a structured questionnaire. The Committee on Human Research Ethics granted prior approval to this research project.

Cervical specimens - Epithelial cells, collected from the cervical surface by scraping with a nylon brush, were transferred to a vial containing $5 \mathrm{ml}$ of TE buffer, TRIS (Life Technologies, Gibco BRL) $10 \mathrm{mM} \mathrm{pH} 7.5$ and EDTA

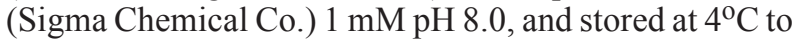
$8^{\circ} \mathrm{C}$ before DNA extraction.

Extraction and precipitation of total DNA - Samples were centrifuged at $2500 \mathrm{~g}$ for $5 \mathrm{~min}$ and the pellet resuspended in $1 \mathrm{ml}$ of TE buffer, followed by digestion with $200 \mu \mathrm{g} / \mathrm{ml}$ proteinase $\mathrm{K}$ (Gibco) for 2 to $4 \mathrm{~h}$ at $55^{\circ} \mathrm{C}$. DNA was extracted by phenol-chloroform (VETEC) as described by Sambrook et al. (1989). Total DNA was precipitated by $100 \%$ ethanol (Reagen) and $5 \mathrm{M} \mathrm{NaCl}$ (Sigma). After incubation for $30 \mathrm{~min}$ at $-80^{\circ} \mathrm{C}$, the vials were centrifuged at $10,000 \mathrm{~g}$ for $15 \mathrm{~min}$. The DNA pellet was washed with $70 \%$ ethanol, dried and re-suspended in TE buffer. Samples were stored at $-80^{\circ} \mathrm{C}$. Whenever samples showed no amplification, other DNA extraction methods were used (Margall et al. 1993, Peyton \& Wheller 1994, Villa et al. 2000).

Detection of HPV DNA by PCR (polymerase chain reaction) - For the detection of HPV DNA, we used the consensus primers MY09 (20 nM) (Gibco) and MY11 (20 nM) (Gibco) (Manos et al. 1989), specific for the L1 ORF region of HPV, $2.5 \mathrm{mM}$ of dNTPs (Gibco) and $2 \mathrm{U}$ of Taq polymerase (Gibco). The primers pCO3 (Gibco) and pCO4 (Gibco), specific for the amplification of a 110 base pairs (bp) fragment of the $\beta$-globin gene, were used as a control of the DNA extraction (Bernard et al. 1994). For standardizing the PCR protocol we used, as positive controls, suspensions of $\mathrm{HeLa}$ and $\mathrm{SiHa}$ cells naturally infected with HPV-18 and HPV-16, respectively, and kindly supplied by the Ludwig Institute for Cancer Research, São Paulo Branch, Brazil. Both distilled water and cervical samples from women with normal cytological reports were used as negative controls. Thirty-nine cycles of amplification were conducted in a MJ Research PTC-100 thermocycler as previously described (Manos et al. 1989).
Samples were submitted to electrophoresis on $1 \%$ agarose gel, followed by $10 \mathrm{mg} / \mathrm{ml}$ ethidium bromide (Sigma) staining for the analysis of the amplified products. Specimens were considered HPV DNA positive if they came within the range of $450 \mathrm{bp}$, when compared to a 100 bp ladder marker, included in each gel (Manos et al. 1989).

2.5. HPV typing - HPV DNA positive samples were typed by restriction fragment length polymorphism (RFLP). The products generated by MY09/MY11 primers were digested by the following enzymes: Bam HI, Dde I, Hae III, Hinf I, Pst I, Rsa I, and Sau 3AI (New England Biolabs ${ }^{\circledR}$ Inc.). The pattern of length polymorphism for each sample was analyzed by electrophoresis on $8 \%$ polyacrylamide (Gibco) gels. The eletrophoretic profile of each sample was compared to the prototypes previously described (Bernard et al. 1994).

Automated sequencing was used to define the HPV type present in some of the samples that could not be characterized by RFLP. The amplified HPV segments were sequenced automatically by the Taq Dye-terminator method either in a Megabace System (AmershamPharmacia) or in an ABI 377 DNA sequencer (Applied Biosystems). Both primers, MY09 and MY11, were used for sequencing each of these samples, generating forward and reverse sequences that could be aligned. Similarity analysis of generated sequences was performed by Basic Local Alignment Search Tool Analysis (BLAST) programs (Altschul et al. 1997) provided by the National Center for Biotechnology Information (http://www.ncbi.nlm. nih.gov).

Statistical analysis - A data bank was generated and analyzed in EPI-Info, 6.04d, from the Centers of Diseases Control and Prevention (CDC). Statistical analysis was also performed by SAS system for frequency, means, logistic procedures and odds ratios estimates. The level of significance of tests ( $\mathrm{p}$ ) was set at 0.05 .

\section{RESULTS}

One hundred and fifty-nine samples were collected in three public hospitals in the Federal District. Thirty samples (19\%) had to be excluded from our study because PCR products for the $\beta$-globin and HPV genes were negative, even when other DNA extraction methods (Margall et al. 1993, Peyton \& Wheller 1994, Villa et al. 2000) were used .

The 129 samples considered in this work were from women aged 17 to 73 (mean 37.0; median 35.0). These women reported that they had had their first intercourse at the age of 12 to 30 years (mean 17.8; median 17.0), and periods of 2 to 59 years (mean 16.2; median 14.0) of sexually active life. The number of sexual partners in the last five years ranged from 0 to 10 (mean 2.0; median 1.0). When considering information about sexually transmitted diseases (STD) informed by 110 subjects, 70\% (77/110) of them answered negatively to diagnosis of STD detected before the last Pap test and 30\% (33/110) answered positively. In the referred STD group, 54.5\% (18/33) had a previous diagnosis of HPV in cytological screening. As regards smoking habits, $70.9 \%(78 / 110)$ were nonsmokers and $29.1 \%(32 / 110)$ indicated that they smoked 3 to 20 cigarettes a day. 
Cytologically diagnosed cervical lesions, were grouped according to severity, as group 1 (G1), for CIN 2 $+\mathrm{CIN} 3+\mathrm{SCC}+\mathrm{ADENO}$, and group 2 (G2), for ASCUS + HPV + CIN $1+$ AGCUS, and showed the following distribution: $73.6 \%(95 / 129)$ of G1 and $26.4 \%(34 / 129)$ of G2. The overall HPV DNA-positive rate was 62.0\% (80/ 129). The prevalence of HPV in G1 was $66.3 \%(63 / 95)$ and $50 \%(17 / 34)$ in $\mathrm{G} 2(\mathrm{OR}=1.97 ; 95 \% \mathrm{CI}=0.82-4.74, \mathrm{p}=0.09)$. The distribution of HPV DNA-positive by cervical lesions cases, grouped by severity of histological diagnosis, is shown in Table I.

\section{TABLE I}

Distribution of cytological diagnosis and human papillomavirus (HPV) DNA positiveness, grouped by severity of lesions

\begin{tabular}{llrcc}
\hline Group & $\begin{array}{l}\text { Cytological } \\
\text { diagnosis }\end{array}$ & $\mathrm{n}$ & $\%$ & $\begin{array}{c}\text { HPV DNA } \\
\text { positiveness } \\
(\%)\end{array}$ \\
\hline $\mathrm{G} 1^{a}{ }^{a}$ & CIN 2 & 29 & 22.5 & \\
& CIN 3 & 53 & 41.1 & \\
& SCC & 6 & 4.6 & \\
& ADENO & 7 & 5.4 & \multirow{6}{*}{ G2 $^{b}{ }^{b}$} \\
& Total (G1) & 95 & 73.6 & $63(66.3)$ \\
& ASCUS & 5 & 4 & \\
& AGCUS & 3 & 2.3 & \\
& HPV & 23 & 17.8 & \\
& CIN 1 & 3 & 2.3 & \\
\hline \multirow{4}{*}{} & Total (G2) & 34 & 26.4 & $17(50)$ \\
\hline & Total (G1 + G2) & 129 & 100.0 & $80(62)$ \\
\hline
\end{tabular}

$a: \mathrm{CIN} 2+\mathrm{CIN} 3+\mathrm{SCC}+\mathrm{ADENO} ; b: \mathrm{HPV}+\mathrm{CIN} 1+\mathrm{ASCUS}$ + AGCUS

Most HPV isolates, $80 \%$ (64/80), were typed by RFLP. Automated sequencing was appropriate to characterize $10 \%(8 / 80)$ of the isolates that could not be typed by RFLP. The other $10 \%(8 / 80)$ could not be typed by either methods and were referred to as HPV-X. We have found 13 different HPV types and HPV-16 was, by far, the most prevalent both in G1 or G2 (Table II). We also detected co-infection with two different HPV types in 3.7\% (3/80) of the cervical smears. They occurred in two samples in G1 (HPV-16 + HPV-CP8061; HPV-53 + HPV-11) and in one in G2 (HPV-16 + HPV-58). The distribution of HPV types detected in both groups of lesions is shown in Table II, which does not include the types detected in co-infections and the ten HPV-X isolates.

The 11 genotypes isolated in single infections were classified in the supergroup A (mucosal/genital) following the phylogenetic tree classification (LANL 1997). A significant association of group A9 that includes HPV types $-16,-31,-33,-52$ and -58 to $\mathrm{G} 1(\mathrm{CIN} 2+\mathrm{CIN} 3+\mathrm{SCC}$ $+\mathrm{ADENO}$ ) could be detected ( $\mathrm{OR}=6.39,95 \%$ IC 1.15 $37.45, \mathrm{p}=0.009)$.

\section{DISCUSSION}

The association between cervical cancer and persistent infection with specific types of HPV is clearly
TABLE II

Human papillomavirus (HPV) types in cervical lesions in Federal District, Brazil

\begin{tabular}{|c|c|c|c|c|c|c|}
\hline \multirow[b]{2}{*}{ HPV types } & \multicolumn{2}{|c|}{$\mathrm{G} 1^{a}$} & \multicolumn{2}{|c|}{$\mathrm{G} 2^{b}$} & \multicolumn{2}{|c|}{ Total } \\
\hline & $\mathrm{n}$ & $\%$ & $\mathrm{n}$ & $\%$ & $\mathrm{n}$ & $\%$ \\
\hline HPV-16 & 29 & 56.8 & 4 & 25 & 33 & 49.2 \\
\hline HPV-18 & 1 & 2 & 2 & 12.5 & 3 & 4.5 \\
\hline HPV-31 & 8 & 15.7 & 0 & 0 & 8 & 11.9 \\
\hline HPV-33 & 2 & 3.9 & 1 & 6.2 & 3 & 4.5 \\
\hline HPV-35 & 0 & 0 & 1 & 6.2 & 1 & 1.5 \\
\hline HPV-52 & 0 & 0 & 1 & 6.2 & 1 & 1.5 \\
\hline HPV-53 & 2 & 3.9 & 2 & 12.5 & 4 & 6.0 \\
\hline HPV-58 & 7 & 13.7 & 2 & 12.5 & 9 & 13.4 \\
\hline HPV-66 & 1 & 2 & 1 & 6.2 & 2 & 3.0 \\
\hline CP8304 & 0 & 2 & 1 & 6.2 & 2 & 3.0 \\
\hline HPV-6b & 1 & 0 & 1 & 6.2 & 1 & 1.5 \\
\hline Total & 51 & 100 & 16 & 100 & 67 & 100 \\
\hline
\end{tabular}

demonstrated in the literature (IARC 1995, Muñoz 2000). Brazilian official statistics indicate that cervical cancer is the third primary neoplasia incident in the Federal District (Brasil 2002). According to the information provided by the National STD and AIDS Program (Brasil 2001), genital condiloma is the most prevalent STD in the Federal District. But although the data indicates a high incidence of HPV findings in cervical samples from women with abnormal cytology reports, no previous study had described the prevalence of HPV types in this population.

The detection of high-risk and low-risk HPVs by the hybrid capture II system (Digene Corporation) has been used by physicians in their private clinics as a tool to predict the prognosis of cervical lesions in women and in penile lesions of their sexual partners. Nevertheless, this method does not produce HPV isolate classification in types (Poljak et al. 1999).

The overall frequency of HPV DNA in this study $(62 \%)$ was lower than that reported by other authors: $76 \%$ (Rabelo-Santos et al. 2003) 78.5\% (Lo et al. 2001), 86.2\% (Lai et al. 1999), and 97\% (Muñoz 2000), but higher than in the Chan et al. (1999) and Riethmuller et al. (1999) reports, which indicate prevalence of $44.3 \%$ and $37.8 \%$, respectively. Cavalcanti et al. (2000) have demonstrated HPV prevalence raging from $85.6 \%$ in low-grade squamous intraepithelial lesions (LSIL) (Broder 1992) to $55.2 \%$ in SCC in a study of Brazilian women with cervical lesions. In Germany, Meyer et al. (1998) reported HPV prevalence of $74 \%$ in LSIL patients and in $88 \%$ of those with highgrade squamous intraepithelial lesions (HSIL) (Broder 1992) indicating a prevalence rate of 1.2 (HSIL/LSIL). Although we could not consider as significant the association of DNA HPV positiveness in the two groups of lesions (G1 and G2), our prevalence rate (1.3) is similar to that reported by Chan et al. (1999).

In single HPV infections, excluding HPV-X, we found that the most frequent HPV types were HPV-16 (49.2\%), HPV-58 (13.4\%), HPV-31 (11.9\%), and HPV-53 (6.07\%). HPV-16 is known to be worldwide prevalent (zur Hausen 
\& Villiers 1994, Bosch et al. 1995, Muñoz 2000) and the frequency of this type in our samples is similar to data reported by other authors, who found $47.8 \%$ (Rolón et al. 2000 ) and $48.8 \%$ (Lo et al. 2001).

A study conducted in Goiânia, among women with cervical intraepithelial neoplasia III and invasive cervical cancer reported a high prevalence $(57.1 \%)$ of HPV-16 (Rabelo-Santos et al. 2003). The authors mentioned that HPV-16 is actually the most prevalent type in all Brazilian regions. However, regarding the other types, a considerable variation can be observed. Our data showed a high prevalence of HPV-58 and HPV-31, which seems to be in accordance with what has been described in the North and Northeast regions of Brazil (Noronha et al. 1999, Lorenzato et al. 2000). Lorenzato et al. (2000) reported a high prevalence $(8.2 \%)$ of HPV-58 among women with cervical lesions compatible with HPV infection in Recife. Noronha et al. (1999) mentioned that HPV-31, -33 and -58 represented $21.2 \%$ of the types identified in individuals with CIN grade II or III. However, the population covered and the methods for virus detection and typing may vary among these studies.

The prevalence of HPV-58 reported by other authors is relatively low compared to HPV-16 and HPV-18 (ElufNeto et al. 1994, Muñoz 2000, Rolón et al. 2000, Lo et al. 2001). In a study of HPV infection at the United StatesMexico border, HPV-16 was the most common type, but HPV-58 was the second most prevalent in the Mexican population, and HPV-18 occupied that position in the American group (Giuliano et al. 2001). Interestingly, a study in Spain found that $75 \%$ of women who tested seropositive for type 58 had been born in a Latin American country (Touze et al. 2001). HPV-58 was also the second most common genotype in Japan (Sasagawa et al. 2001) and in China (23.8\%), with a significant trend to increased prevalence in line with the increasing severity of lesions (Chan et al. 1999). In Paraguay, which borders of Southern Brazil, HPV-58 was detected in $2.7 \%$ of cervical carcinomas (Rolón et al. 2000). In our work, the prevalence rate of HPV-58 in G1 and G2 was 3.5 ( $p=0.027)$. So, different areas in South America may have significant variations in the prevalence of different HPV types. Lai et al. (1999) questioned whether HPV-58 may be partially responsible for cervical cancer in the older population in East Asia and urged further investigation on the natural history of HPV-58-related cervical neoplasias.

Prevalence of HPV-18 (4.5\%) and -31 (11.9\%) differed from that reported by Bosch et al. (1995) and Rolón et al. (2000) who cited prevalence of $14 \%$ and $5 \%$, and $10 \%$ and $3.5 \%$, respectively. Reports that HPV-18 was more prevalent in adenocarcinomas (Bosch et al. 1995, van Muyden et al. 1999, Lo et al. 2001, Sasagawa et al. 2001) could not be confirmed because insufficient samples of those lesions were available in the population included in our work.

In the present study, infection with A9 phylogenetic group HPVs $(-16,-31,-35,-33,-52,-58)$ may indicate a less favorable prognosis for cervical lesions, detected by cytological screening, since the association of A9 HPVs to $\mathrm{G} 1$ lesions was significant ( $\mathrm{OR}=6.39 \%, 95 \%$ CI 1.15 37.42).
The high-risk HPV types detected are compatible to the cytological diagnosis reports considered for inclusion criteria. Also, the frequency of high and low risk HPV types in the pre-malignant and malignant cervical samples, observed in our study, emphasize the importance of genotyping for a more accurate prognosis of these lesions. We wish to emphasize that the prevalence of HPV-58, in the North, Northeast, and Central Brazil, should be considered if prophylactic HPV vaccine trials, based on a cocktail of a limited number of types, are to be run in this population. In order to establish associations between more rare HPV types and the risk of cervical cancer, casecontrol studies are recommended.

\section{ACKNOWLEDGMENTS}

To Luísa Villa, for technical assistance and John Penney for reviewing the manuscript.

\section{REFERENCES}

Altschul SF, Madden TL, Schäffer AA, Zhang Z, Miller W, Lipman DJ 1997. Gapped BLAST and PSI-BLAST: a new generation of protein database search programs. Nucleic Acid Research 25: 3389-3402.

Bernard HU, Chan SY, Manos MM, Ong CK, Villa LL, Delius H, Peyton DL, Bauer HM, Wheller CM 1994. Identification and assessment of known and novel human papillomaviruses by polymerase chain reaction amplification, restriction fragment length polymorphisms, nucleotide sequence and phylogenetic algorithms. J Infect Dis 170: 1077-1085.

Bosch FX, Manos MM, Munoz N, Sherman M, Jansen AM, Peto J, Schiffman MH, Moreno V, Kurman R, Shah KV 1995. Prevalence of human papillomavirus in cervical cancer: a worldwide perspective. International biological study on cervical cancer (IBSCC) study group. J Natl Cancer Inst 87: 796-802.

Brasil, Ministério da Saúde, Coordenação Nacional de DST e Aids 2001. Available at internet: http://www.aids.gov.Br/ final/dados/DST\%20estudos.

Brasil, Ministério da Saúde, Instituto Nacional de Câncer 2002. Available at: http://www.inca.gov.br/cancer/epidemiologia/ estimativa2002/brasil.html

Broder S 1992. The Bethesda system for reporting cervical/ vaginal cytologic diagnosis-report of the 1991 Bethesda Workshop. JAMA 267: 1892.

Cavalcanti SM, Zando LG, Passos MR, Oliveira LH 2000. Epidemiological aspects of human papillomavirus infection and cervical cancer in Brazil. J Infect 40: 80-87.

Chan PKS, Li WH, Ma WI, Cheung JLK, Cheng AF 1999. High prevalence of human papillomavirus type 58 in Chinese women with cervical cancer and pre-cancerous lesions. $J$ Med Virol 59: 232-238.

Eluf-Neto J, Booth M, Muñoz N, Bosch FX, Meijer CJLM, Walbooners JMM 1994. Human papillomavirus and invasive cervical cancer in Brazil. Brit J Cancer 69: 114-119.

Giuliano AR, Papenfuss M, Abrahamsen M, Denmanc C, de Zapien JG, Henze JLN, Ortega L, de Gala EMB, Stephan J, Feng J, Baldwin S, Garcia F, Hatch K 2001. Human papillomavirus infection at the United States-Mexico border: implications for cervical cancer prevention and control. Cancer Epidemiol Biomarkers and Prevention 10: 11291136.

Hagensee ME 1999. Human papillomavirus vaccine. Infect Urol 12: 11-19.

Hwang T 1999. Detection and typing of human papillomavirus DNA by PCR using consensus primers in various cervical 
lesions of Korean women. J Korean Medical Science 24: 593-599.

IARC-International Agency for Research on Cancer 1995. Monographs on the evaluation of the carcinogenic risks to humans, vol. 64. Human papillomavirus. International Agency for Research on Cancer, Lyon.

Lai HG, Sun CA, Yu MH, Chen HJ, Liu HS, Chu TY 1999. Favorable clinical outcome of cervical cancers infected with human papillomavirus type 58 and related types. Int $J$ Cancer (Pred Oncol) 84: 553-557.

LANL-Los Alamos National Laboratory, US 1997. http://hpvweb.lanl.gov. HPV Sequence Database. HPV Compendium part I, p. 1- 7.

Lo KWK, Cheung TH, Chung TKH, Wang VW, Poon JS, Li JCB, Lam P, Wong YF 2001. Clinical and prognostic significance of human papillomavirus in a Chinese population of cervical cancers. Gyn Obst Investigation 51: 202-207.

Lorenzato F, Ho L, Terry G, Singers A, Santos LC, De Lucena Batista R, Lubambo T 2000. The use of human papillomavirus typing in detection of cervical neoplasia in Recife (Brazil). Int J Gynecol Cancer 10: 143-150.

Lorincz AT, Reid R, Jenson AB, Greenburg MD, Lancaster W, Kurman RJ 1992. Human papillomavirus infection of the cervix. Obst gynecol 79: 328-337.

Manos MM, Ting Y, Wright DK, Lewis AJ, Broker TR, Wolinsky SM 1989. Use of polymerase chain reaction amplification for the detection of genital human papillomaviruses. Mol Diagn Human Cancer Cells 7: 209214.

Mansur CP 2001. Molecular mechanisms of HPV-associated oncogenesis. In JC Sterling, SK Tying (eds), Human Papillomaviruses - Clinical and Scientific Advances, Arnold, London, p. 24-32.

Margall N, Matias-Guiu X, Chillon M, Coll P, Nunes MAV, Quilez M, Rabella N, Prats G, Prat J 1993. Detection of human papillomavirus 16 and 18 DNA in epithelial lesions of the lower genital tract by in situ hybridization and polymerase chain reaction: cervical scrapes are not substitutes for biopsies. J Clin Microbiol 31: 924-930.

Meyer T, Arndt R, Christophers E 1998. Association of rare papillomavirus types with genital premalignant and malignant lesions. J Infect Dis 178: 252-255.

Muñoz N 2000. Human papillomavirus and cancer: the epidemiological evidence. J Clin Virol 19: 1-5.

Noronha V, Mello W, Villa LL, Macedo R, Bisi F, Mota R, Sassamoto K, Monteiro T, Linhares A 1999. Human papillomavirus associated with cervix lesions. Rev Soc Bras Med Trop 32: 235-240.

Peyton CL, Wheller CM 1994. Identification of five novel human papillomavirus sequences in the New Mexico triethnic population. J Infect Dis 170: 1089-1092.

Poljak M, Brencic A, Seme K, Vince A, Marin IJ 1999. Com- parative evaluation of first and second-generation digene hybrid capture assays for detection of human papillomaviruses associated with high or intermediate risk for cervical cancer. J Clin Microbiol 37: 796-797.

Qu W, Jiang G, Cruz Y, Chang CJ, Ho GYF, Klein RS, Burck RD 1997. PCR detection of human papillomavirus: comparison between MY9/MY11 and GP5+/GP6+ primer systems. J Clin Microbiol 35: 1304-1310.

Rabelo-Santos SH, Zeferino L, Villa LL, Sobrinho JP, Amaral RG, Magalhães AV 2003. Human papillomavirus prevalence among women with cervical intraepithelial neoplasia III and invasive cervical cancer from Goiânia, Brazil. Mem Inst Oswaldo Cruz 98: 181-184.

Riethmuller D, Gay C, Bertrand X, Bettinger D, Schaak JP, Carbillet JP, Lassable C, Arveux P, Seilles E 1999. Genital human papillomavirus infection among women recruited for cervical cancer screening or for colposcopy determined by hybrid capture II and polymerase chain reaction. Diag Molec Pathol 8: 157-164.

Rolón PA, Smith JS, Muñoz N, Kugg SJ, Herrero R, Bosch X, Lamosas F, Meijer CJLM, Walboomers JMM 2000. Human papillomavirus infection and invasive cervical cancer in Paraguay. Int J Cancer 85: 486-491.

Sambrook J, Fritsch EF, Maniatis T 1989. Molecular Cloning: A Laboratory Manual, 2nd ed., Cold Spring Harbour Laboratory Press, New York.

Sasagawa T, Basha W, Yanazaki H, Inoue M 2001. High-risk and multiple human papillomavirus infections associated with cervical abnormalities in Japanese women. Cancer Epidemiology Biomarkers \& Prevention 10: 45-52.

Sherman ME, Schiffman MH, Lorincz AT, Manos MM, Scott DR, Kurman RJ, Kiviat NB, Stoler M, Glass AG, Rush BB 1994. Toward objective quality assurance in cervical cytopathology: correlations of cytopathologic diagnoses with detection of high-risk Human papillomavirus types. Am J Clin Pathol 102: 182-187.

Touze A, de Sanjose S, Coursaget P, Almirall MR, Palacio V, Meijer CJL, Kornegay J, Bosch FX 2001. Prevalence of anti-human papillomavirus type 16, 18, 31 and 58 viruslike particles in women in the general population and in prostitutes. J Clin Microbiol 39: 4344-4348.

van Muyden RCPA, ter Harmsel BWA, Smedts FMM, Hermans J, Kuijpers JC, Raikhlin NT, Petrov S, Lebedev A, Ramaekers FCS, Trimbos JB, Kleter B, Quint WGV 1999. Detection and typing of Human papillomavirus in cervical carcinomas in Russian women - A prognostic study. Cancer 85: 2011-2016.

Villa LL, Sichero L, Rahal P, Caballero O, Ferenczy A, Rohan T, Franco E 2000. Molecular variants of human papillomavirus types 16 and 18 preferentially associated with cervical neoplasia. J Gen Virol 81: 2959-2968.

zur Hausen H, Villiers EM 1994. Human papillomaviruses. Annu Rev Microbiol 48: 427-447. 